\title{
QUILOMBOS PAULISTAS: A política pública de Assistência Técnica e Extensão Rural (ATER) em sua interface com as comunidades tradicionais frente ao projeto de lei estadual n 529 de 2020
}

QUILOMBOS PAULISTAS: The public policy of technical assistance and rural extension (ATER) in its interface with traditional communities in the face of São Paulo State bill n 529 of 2020

QUILOMBOS PAULISTAS: La política pública de asisten-cia técnica y extensión rural (ATER) en su interfaz con las comunidades tradicionales frente al proyecto de ley del Estado de São Paulo nº 529 de 2020

\section{Eduardo Festozo Vicente}

Professor Assistente Doutor junto à Faculdade de Ciências e Engenharia - FCE, UNESP Tupã, SP. eduardo.vicente@unesp.br.

0000-0002-9154-3574

\section{Silvia Cristina Vieira Gomes}

Mestra e Doutoranda do Programa de Pós Graduação em Agronegócio e Desenvolvimento - FCE, UNESP Tupã, SP. silvia.cv.gomes@unesp.br.

0000-0003-2413-556X

\section{Paula Garcia Lima}

Doutoranda em Educação, Arte e História da Cultura Mestra e Doutoranda do Programa de Pós Graduação em Agronegócio e Desenvolvimento - FCE, UNESP Tupã, SP. paulatulipa@hotmail.com.

\section{0-0001-9770-4976}

Correspondência: Universidade Estadual Paulista Faculdade de Ciências e Engenharia / UNESP - Câmpus de Tupã. R. Domingos da Costa Lopes, 780 - Jardim Itaipu, Tupã - SP, 17602-496 - Brasil.

Recebido em: 12.10.2020.

Aceito em: 20.11.2020.

Publicado em: 01.01.2021.

\begin{abstract}
RESUMO:
As comunidades remanescentes de quilombo no Estado de São Paulo correm severo risco de alterações negativas na prestação de serviços de extensão rural oficial com o advento do Projeto de Lei (PL) $n^{\circ}$ 529/2020. Assim, o objetivo deste trabalho é buscar como as comunidades tradicionais remanescentes de quilombos localizadas no estado de São Paulo podem ser diretamente prejudicadas com o PL 529 de 2020. Para tanto, foi adotada metodologia de caráter científico, o qual se resume a revisão bibliográfica e documental de caráter descritivo e exploratório. Como resultado, nenhum fato ou argumento foi encontrado para legitimar o Projeto de Lei $n^{\circ} 529$ de 2020 dentro da perspectiva das comunidades tradicionais e demais beneficiários da política pública de ATER paulista.
\end{abstract}

PALAVRAS-CHAVES: Comunidades tradicionais; Extensão rural; Quilombos paulistas.

\section{Introdução}

A política pública de Assistência Técnica e Extensão Rural (ATER) no Brasil encontrase parametrizada em especial pela Política Nacional de Assistência Técnica e Extensão Rural (PNATER), executada com base no Programa Nacional de Assistência Técnica e Extensão Rural (PRONATER). Possui, em seu quadro de público alvo prioritário, o atendimento às comunidades quilombolas, de acordo com Vieira et al. (2020) e Vieira (2016), respaldados por meio da jurisprudência de Brasil (2004; 2005; 2010).

Em território paulista, com a publicação do Projeto de Lei (PL) número 529, de 13 de agosto de 2020, as comunidades tradicionais tendem a sofrer uma penalização no atendimento da ATER. Isto pode ocorrer devido às novas condições estruturais, com proposta de extinção da base oficial deste tipo de atendimento, desmonte da Coordenadoria de Desenvolvimento Rural Sustentável (CDRS) e Fundação Instituto de Terras do Estado de São Paulo (ITESP) (SP, 2020). 
As comunidades remanescentes de quilombos possuem uma tradição de cultivo agrícola enraizada em sua própria história. Neste sentido, o apoio da ATER favorece um modelo de produção contemporâneo, sem perder os parâmetros sustentáveis do cultivo do passado, como orientação integralizada na PNATER. Esta, por sua vez, possui como base elementar o cultivo agroecológico e fomento da qualidade de vida dos atendidos, os quais são descritos na Legislação Federal em Brasil (2004) e confirmado por Caporal e Costabeber, (2004); Vieira (2016); Vieira et al. (2020), com respaldo de Olinger (2020). Todos os documentos refletem uma consonância e respeito aos parâmetros culturais e o modo de vida sustentável das comunidades tradicionais.

Desta forma, a ATER tende a possibilitar a essas comunidades tornarem-se mais produtivas, tanto para o abastecimento local quanto para comercialização do excedente. Portanto, a política pública de ATER é um direito fundamental, garantido por meio do arcabouço legal, destinada para um público alvo específico e prioritário, onde se encontram inseridas as comunidades remanescentes de quilombos no Brasil (VIEIRA, 2016; BRASIL, 2004; 2005; 2010). Tal política pública é, portanto, essencial para a manutenção destas comunidades tradicionais. Atualmente, estas encontram-se ameaçadas por meio do PL 529/2020.

Historicamente, as "comunidades quilombolas vêm lutando pelo direito de serem agentes de sua própria história. Em tal situação de desigualdade, os grupos minoritários passam a valorar positivamente seus traços culturais diacríticos e suas relações coletivas" (SCHMITT; TURATTI; CARVALHO, 2002, p. 5). Desta forma, é neste cenário de conflagrações sociais que emerge a relação das comunidades quilombolas com a terra e a produção de alimentos.

Diante do exposto, surge a seguinte questão norteadora para esta pesquisa: o PL $n^{\circ} 529 / 2020$ poderá maleficiar as comunidades quilombolas paulistas no tocante aos atendimentos de ATER?

Posto isto, este estudo tem como objetivo geral buscar como as comunidades tradicionais remanescentes de quilombos localizadas no estado de São Paulo podem ser diretamente prejudicados com o PL n 529/2020. Especificamente, busca-se:

a) Mensurar os quilombos do Estado de São Paulo que serão prejudicados com o PL n 529/2020;

b) Pontuar os benefícios da política pública de ATER para povos quilombolas.

\section{Trajetória metodológica}


A base metodológica adotada nesta pesquisa, de caráter científico, está ancorada em Gerhardt e Silveira (2009) e resume-se a uma trajetória estrutural do tipo revisão bibliográfica, com apoio de revisão documental e com respaldo da legislação da ATER nacional. Quanto ao objetivo metodológico, Marconi e Lakatos (2013), reforçadas por Gil, (2014) enquadram o estudo como sendo uma pesquisa exploratória, pois terá por objetivo familiarizar-se com o cotidiano da ATER paulista, obtendo um panorama atual insólito. Além disso, será também descritiva, por realizar narrativas das situações, especificar e averiguar as relações existentes entre os elementos que compõem esta pesquisa.

Quanto aos resultados, apresentam-se por meio de abordagem qualitativa, pois dispensa a utilização de métodos estatísticos (MARCONI; LAKATOS, 2013). Embora aborde uma temática nacional, o espaço geográfico da pesquisa está focalizado no Estado de São Paulo, devido ao PL ser uma peça jurídica exclusivamente paulista.

Com início no mês de agosto e término em novembro de 2020, tal pesquisa teve sua finalização antes de uma decisão definitiva do projeto de lei, mas traz fatos e consequências atualizados. Desta maneira, pretende-se que esta abordagem sirva de base conceitual para o desenvolvimento de futuros trabalhos, com conclusão dos impactos do PL n 529/2020 sobre a ATER em territórios quilombolas no Estado de São Paulo.

\section{Desenvolvimento}

\section{A política pública de ATER nacional}

Para Rua (2006), as políticas públicas são resultados de atividades políticas com decisões e ações; portanto, torna-se relevante o discernimento de política pública e decisão política. Nesse sentido, a autora ressalva que:

\footnotetext{
Uma política pública geralmente envolve mais do que uma decisão e requer diversas ações estrategicamente selecionadas para implementar as decisões tomadas. Já uma decisão política corresponde a uma escolha, entre um leque de alternativas, conforme a hierarquia das preferências dos atores envolvidos, e expressa - em maior ou menor grau - uma certa adequação entre os fins pretendidos e os meios disponíveis (RUA, 2006 p. 232)
}

Vale ressaltar que as definições e conceitualizações de políticas públicas no papel de "solução de problemas públicos" são muitas vezes carregadas de críticas, já que provém de atividades políticas com interesses políticos. Isto cria um conflito em torno das ideias e interesses dos governos e deixa para trás a essência da política pública (SOUZA, 2006). Estes conflitos de ideias e interesses governamentais ilustram exatamente 
o que vem ocorrendo no case do PL no 529/2020, onde há claramente uma tentativa de desmonte nos atendimentos de ATER público no Estado de São Paulo. Assim, este PL não leva em consideração as demandas da população rural, com foco em pequenos produtores que compõe o público beneficiário da política pública de ATER.

Figura 1 Linha do tempo da ATER brasileira.

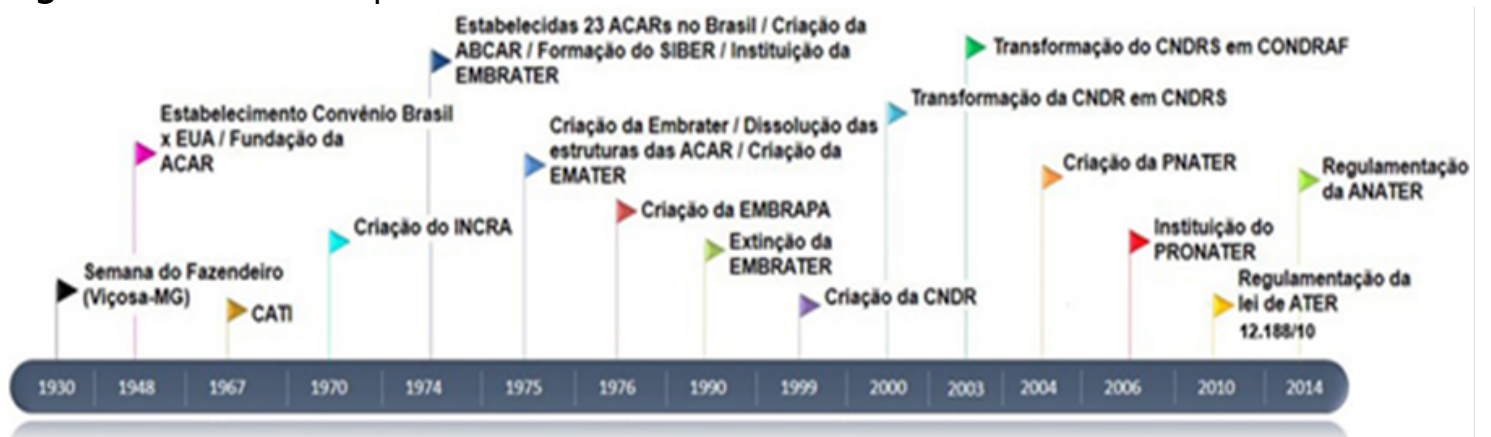

\begin{tabular}{|c|c|}
\hline \multicolumn{2}{|l|}{ Legenda } \\
\hline 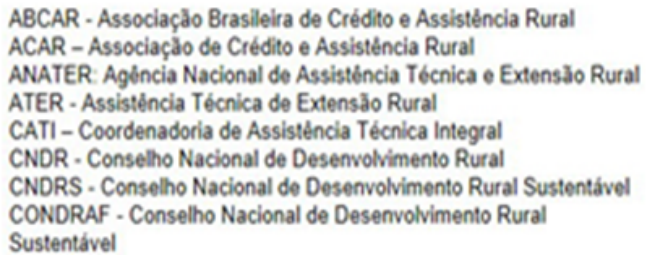 & 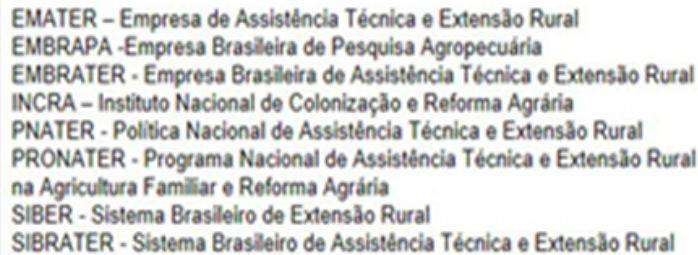 \\
\hline
\end{tabular}

Fonte: Vieira (2016).

Devido ao resgate temporal da pesquisa de Vieira, (2016), a Figura 1 ausenta a alteração do nome do CATI por CDRS no ano de 2019 e o PL n 529/2020. Para este ensaio, adotou-se o conceito da referência oficial de Assistência Técnica e Extensão Rural brasileira por meio do Artigo 2, Lei $\mathrm{n}^{\circ}$ 12.188, de 11 de janeiro de 2010, regulamentada pelo Decreto $\mathrm{n}^{\circ} 7.215$ de 15 de junho do mesmo ano, definindo a ATER como sendo um:

Serviço de educação não formal, de caráter continuado, no meio rural, que promove processos de gestão, produção, beneficiamento e comercialização das atividades e dos serviços agropecuários e não agropecuários, inclusive das atividades agroextrativistas, florestais e artesanais (BRASIL, 2010, p. 1).

Para os atendimentos de ATER, com base legal em Brasil (2004; 2005), as orientações estratégicas da PNATER são:

i) Promover o desenvolvimento rural sustentável;

ii) Gratuidade, qualidade e acessibilidade aos serviços de ATER;

iii) Adoção de metodologia participativa com enforque multi e interdisciplinar e intracultural; 
iv) Adoção dos princípios da agricultura de base ecológica, deforma preferencial;

v) Equidade nas relações de gênero, geração e etnia;

vi) Contribuir para a segurança e soberania alimentar e nutricional.

Nota-se que todos os itens abordados como orientação estratégica para os atendimentos da política pública de ATER possuem aderência às demandas dos beneficiários das comunidades quilombolas paulistas.

\section{Fundação Instituto de Terras do Estado de São Paulo "José Gomes da Silva" - ITESP e Comunidades Quilombolas}

Por meio da Lei n 10.207/99, foi criada a fundação ITESP que, conforme artigo $3^{\circ}$, é responsável por:

\footnotetext{
I - promover a regularização fundiária em terras devolutas ou presumivelmente devolutas, nos termos da legislação vigente; II - implantar assentamentos de trabalhadores rurais, nos termos da Lei n 4.957, de 30 de dezembro de 1985, e legislação complementar; III - prestar assistência técnica às famílias assentadas e aos remanescentes das comunidades de quilombos, assim identificados; IV - identificar e solucionar conflitos fundiários;

V - promover a capacitação de beneficiários e de técnicos, nas áreas agrária e fundiária;

VI - promover a identificação e a demarcação das terras ocupadas por remanescentes das comunidades de quilombos, para fins de regularização fundiária, bem como seu desenvolvimento socioeconômico; e

VII - participar, mediante parceria, da execução das políticas agrária e fundiária, em colaboração com a União, outros Estados e municípios. (BRASIL, 1999, p.1).
}

A importância da fundação ITESP para as comunidades remanescentes quilombolas vai além das ações de promoção da cidadania e sustentabilidade: também está associada à mediação de conflitos fundiários, no sentido de garantir o direito às terras ocupadas que, após o reconhecimento e titulação, fornece a estes remanescentes garantias sobre a permanência definitiva nestas áreas (SÃO PAULO, sd).

Por meio da Constituição Brasileira de 1988, ocorreu o reconhecimento ao direito da titulação das comunidades quilombolas: "Não obstante, empreenderam-se discussões sobre quem são e como podem ser entendidos e identificados os 'remanescentes de quilombos', questionando-se a definição do conceito no artigo constitucional" (CARRIL, 2017, p. 541). Assim, foi por meio do Decreto $n^{\circ}$. 4.887/2003 que possibilitou "regulamentar o procedimento para identificação, reconhecimento, delimitação, demarcação e titulação das terras ocupadas por remanescentes das comunidades dos 
quilombos" (BRASIL, 2003, p.1). Diante do exposto, o Decreto $n^{\circ} 4.887$ de 20 de novembro de 2003, em seu Artigo $2^{\circ}$, consideram as comunidades quilombolas como:

Consideram-se remanescentes das comunidades de quilombo, os grupos étnicos raciais, com o critério de auto-atribuição, com trajetória histórica própria, dotados de relações territoriais específicas, com presunção de ancestralidade negra, relacionada com a resistência a opressão sofrida (BRASIL, 2003, p. 17).

A ancestralidade negra comum confere a esse grupo étnico uma trajetória histórica exclusiva e "em seus territórios eles se autodenominam como comunidades de quilombos, devido suas características de costume de tradições e condições sociais, culturais, econômicas específicas que distinguem do restante da sociedade" (PEREIRA; MENDES, 2017, p. 1-2).

Em sua base conceitual, os quilombos podem ser definidos com comunidades negras localizadas em espaços rurais ou urbanos habitados por descendentes de africanos escravizados, que possuem laços de parentesco, onde prevalece a forma de uso comum das terras onde se realiza o cultivo de subsistência, o cultivo agrícola por meio da agricultura familiar coletiva, a criação de animais de produção, a pesca e o extrativismo para a sobrevivência da comunidade (MOURA, 2007).

Tal conceito cunhado por Moura (2007), que aborda o viés produtivo agropecuário dos quilombos, confirma a importância dos atendimentos de ATER visando a geração do etnodesenvolvimento. Além disso, sua descrição enquadra as comunidades quilombolas como público alvo prioritário dos atendimentos de ATER Setorial, já apontados por Brasil (2004; 2010) nesta pesquisa.

Em relatos hodiernos sobre as dificuldades enfrentadas pelas comunidades remanescentes de quilombos, Carril (2017, p. 542) aponta que "as lutas na contemporaneidade exigem reparações e o reconhecimento social e jurídico de garantia à inserção social dos grupos e indivíduos privados de direitos".

Nota-se que, a partir do PL n 529/2020, as privações de direito das comunidades quilombolas, no tocante à política pública de ATER, tende a estar comprometida, embora tenham garantia jurídica por meio do arcabouço legal da PNATER e do PRONATER, legitimando o grupo étnico como beneficiário dos atendimentos de maneira gratuita e ininterrupta: encontra respaldo legal no Artigo 2, Lei no 12.188, de 11 de janeiro de 2010, regulamentada pelo Decreto $\mathrm{n}^{\circ} 7.215$, de 15 de junho do mesmo ano. 


\section{Resultados e Discussões}

Nota-se uma lacuna informacional sobre o número exato de quilombolas no Brasil. Para mitigar esta lacuna, a métrica oficial passará a ser validada por meio do Censo de 2020. Anteriormente, em outras edições censitárias, as comunidades quilombolas do Brasil não integravam a base de dados do Censo Demográfico, promovido pelo Instituto Brasileiro de Geografia e Estatística (IBGE). Sobre a temática, a Fundação Cultural Palmares (sd, p. 1) relata que "os resultados sobre povos e comunidades tradicionais deverão ser disponibilizados em 2022". Mesmo na ausência de dados oficiais do IBGE, o Estado de São Paulo mensurou 36 comunidades remanescentes de quilombo. Neste contexto, seis destas comunidades foram tituladas em terras públicas estaduais, somando um número superior a 1,4 mil famílias que vivem nestas comunidades, permeando 14 municípios paulistas, descritos no Quadro 1.

Embora a ATER pública paulista tenha sua coordenação central na governança da Secretaria da Agricultura e Abastecimento do Estado de São Paulo, é por meio da Coordenadoria de Desenvolvimento Rural Sustentável (CDRS), antiga Coordenadoria de Assistência Técnica Integral (CATI), que ocorre a predominância dos atendimentos de assistência técnica rural pública gratuita.

Quadro 1 Comunidades remanescentes de quilombo no Estado de São Paulo.

\begin{tabular}{|c|c|c|c|c|c|}
\hline$N^{\circ}$ & Comunidade & Município & Famílias & $\begin{array}{l}\text { Área } \\
\text { (ha) }\end{array}$ & Reconhecido \\
\hline 1 & Ivapotunduva & Eldorado & 98 & $2.754,36$ & 1998 \\
\hline 2 & Maria Rosa & Iporanga & 25 & $3.375,66$ & 1998 \\
\hline 3 & Pedro Cubas & Eldorado & 40 & $3.806,23$ & 1998 \\
\hline 4 & Pilões & Iporanga & 63 & $6.222,30$ & 1998 \\
\hline 5 & São Pedro & Eldorado/Iporanga & 39 & $4.688,26$ & 1998 \\
\hline 6 & Cafundó & Salto de Pirapora & 24 & 209,64 & 1999 \\
\hline 7 & Caçandoca & Ubatuba & 50 & 890,00 & 2000 \\
\hline 8 & Jaó & Itapeva & 53 & 165,77 & 2000 \\
\hline 9 & André Lopes & Eldorado & 76 & $3.200,16$ & 2001 \\
\hline 10 & Nhunguara & Eldorado/Iporanga & 91 & $8.100,98$ & 2001 \\
\hline 11 & Sapatu & Eldorado & 82 & $3.711,62$ & 2001 \\
\hline 12 & Galvão & Eldorado/Iporanga & 34 & $2.234,34$ & 2001 \\
\hline 13 & Mandira & Cananéia & 16 & $2.054,65$ & 2002 \\
\hline 14 & Praia Grande & Iporanga & 34 & $1.584,83$ & 2002 \\
\hline 15 & Porto Velho & Iporanga & 19 & 941,00 & 2003 \\
\hline 16 & $\begin{array}{l}\text { Pedro Cubas de } \\
\text { Cima }\end{array}$ & Eldorado & 22 & $6.875,22$ & 2003 \\
\hline 17 & Capivari & Capivari & 17 & 6,93 & 2004 \\
\hline 18 & Brotas & Itatiba & 32 & 12,48 & 2004 \\
\hline 19 & Cangume & Itaóca & 37 & 724,60 & 2004 \\
\hline 20 & Camburi & Ubatuba & 39 & 972,36 & 2005 \\
\hline 21 & Morro Seco & Iguape & 47 & 164,69 & 2006 \\
\hline
\end{tabular}




\begin{tabular}{|c|l|l|c|c|c|}
\hline 22 & Poça & $\begin{array}{l}\text { Eldorado/ } \\
\text { Jacupiranga }\end{array}$ & 41 & $1.126,14$ & 2008 \\
\hline 23 & $\begin{array}{l}\text { Ribeirão Grande/ } \\
\text { Terra Seca }\end{array}$ & Barra do Turvo & 77 & $3.471,04$ & 2008 \\
\hline 24 & Cedro & Barra do Turvo & 23 & $1.066,11$ & 2009 \\
\hline 25 & Reginaldo & Barra do Turvo & 94 & $1.279,68$ & 2009 \\
\hline 26 & $\begin{array}{l}\text { Pedra } \\
\text { Preta/Paraiso }\end{array}$ & Barra do Turvo & 80 & $3.280,26$ & 2009 \\
\hline 27 & $\begin{array}{l}\text { Sertão de } \\
\text { Itamambuca }\end{array}$ & Ubatuba & 31 & 509,94 & 2010 \\
\hline 28 & Peropava & Registro & 25 & 395,98 & 2011 \\
\hline 29 & Bombas & Iporanga & 16 & $2.512,73$ & 2014 \\
\hline 30 & 30. Aldeia & Iguape & 17 & $7.350,63$ & 2014 \\
\hline 31 & $\begin{array}{l}\text { Abobral Margem } \\
\text { Esquerda }\end{array}$ & Eldorado & 38 & $3.459,23$ & 2014 \\
\hline 32 & Engenho & Eldorado & 15 & 534,11 & 2014 \\
\hline 33 & Ex Colonia Velha & Cananéia & 10 & $2.399,02$ & 2015 \\
\hline 34 & Biguazinho & Miracatu & 9 & 792,47 & 2018 \\
\hline 35 & Piririca & Iporanga & 14 & $1.081,50$ & 2018 \\
\hline 36 & Ostra & Eldorado & 17 & 238,63 & 2018 \\
\hline
\end{tabular}

Fonte: São Paulo, (sd) com dados da Fundação ITESP.

Para as comunidades remanescentes de quilombos em terras paulistas apresentadas no Quadro 1, a ATER é realizada de maneira customizada por meio da Fundação ITESP, a qual possui, em seu rol de atribuições:

Promover a capacitação dos beneficiários quilombolas, complementada com políticas públicas de desenvolvimento em atividades agrícolas, manejo florestal, produção artesanal, comercialização, infraestrutura, com ações nas searas da saúde, educação, gestão social, meio ambiente, turismo, com incentivo a autonomia de acordo com o "modus vivend", em respeito às suas tradições (SÃO PAULO, sd).

Entre seus benefícios, os atendimentos de ATER favorecem o etnodesenvolvimento das comunidades quilombolas. Assim, o etnodesenvolvimento é trabalhado principalmente no nível local, "justamente porque é nesse nível onde existem maiores oportunidades para os grupos étnicos exercerem influência nas decisões que lhes afetam". Este é o primeiro passo para promover mudanças nas suas práticas econômicas e sociais (LITTLE, 2002, p. 40). Desta forma, a política pública de ATER permeia este viés desenvolvimentista. 
As primeiras sistematizações sobre etnodesenvolvimento surgiram em 1981, na Reunião de Peritos de Etnodesenvolvimento e Etnocídios, na América Latina, em Barbados. O objetivo daquela Reunião era criar a possibilidade de pensar um desenvolvimento que fosse adequado à condição étnica de cada sociedade, isto é, um desenvolvimento com etnicidade. Ela teve sucesso com a sólida contribuição de antropólogos e sociólogos e instituições como a Faculdade Latino-Americana de Ciências Sociais - Flacso e Organização das Nações Unidas - ONU (ALMEIDA, 2017, p. 138).

Nesta pesquisa, o etnodesenvolvimento é lembrado face à capacitação dos beneficiários, produção de alimentos sustentáveis, à organização social, viés que reforça a consolidação das diversidades étnicas e culturais, de maneira customizada nos atendimentos aos quilombos paulistas, reforçando o modo de vida das comunidades tradicionais, segundo citação de São Paulo (sd). O desenvolvimento do território e a qualidade de vida da comunidade quilombola são fatores a serem considerados nos atendimentos de ATER.

Além dos benefícios específicos da política pública de ATER, o ITESP também possui atribuições tipificadas para outros interesses dos povos quilombolas, como reconhecimento oficial destas comunidades e a regularização de suas áreas (SÃO PAULO, sd). Estes trabalhos, de maneira geral, potencializam o resgate cultural e o sentimento de pertencimento, os quais tendem a fomentar o etnodesenvolvimento.

As políticas públicas são consideradas decisões sobre problemas públicos; porém, as ações e decisões nesta dimensão "pública" podem vir "revestidas da autoridade e soberania do poder público" (RUA, 2006, p. 232). Portanto, espera-se que o poder público repense as ações propostas no PL no 529/2020, mantendo a amplitude legal dos atendimentos da política pública de ATER aos beneficiários paulistas.

Na visão de Saravia (2006), a política pública:

[...] é um sistema de decisões públicas que visa a ações ou omissões, preventivas ou corretivas, destinadas a manter ou modificar a realidade de um ou vários setores da vida social, por meio da definição de objetivos e estratégias de atuação e da alocação dos recursos necessários para atingir os objetivos estabelecidos (SARAIVA, 2006, p. 29).

Neste sentido, caso realmente forem aceitas as ações previstas no PL 529/2020, tenderá a ocorrer omissão do Estado no tocante aos objetivos e estratégias de atuação da política pública de ATER, seguindo os parâmetros de desenvolvimento sustentável. A base de ações sustentáveis nos atendimentos de ATER no campo são preconizados na PNATER, com base na aplicabilidade das ações por meio do PRONATER, apresentados 
por Brasil (2004; 2010), confirmados por Caporal e Costabeber, (2004) e ressaltados por Vieira et al. (2020).

Embora múltiplos esforços busquem a mitigação danosa do PL n 529/2020, ainda não é possível citar ações concretas oficiais que anulem ou minimizem seus aspectos negativos no viés da ATER paulista para os atendimentos da população afrodescendente, caracterizada também como povos tradicionais e que possuem suas comunidades localizadas no espaço geográfico do Estado de São Paulo.

\section{Considerações Finais}

A mensuração governamental contabilizou 1.445 famílias que vivem nestas comunidades, perfazendo uma área total de 79.794,53 ha, localizadas em 14 municípios paulistas, nas quais já foram reconhecidas 36 comunidades. Estas comunidades, por sua vez, seriam duramente penalizadas, não somente no viés da ATER, mas também em outros benefícios complementares que possuem estreito vínculo com a assistência e apresentam-se diretamente ligados à promoção do etnodesenvolvimento. Na busca de mitigar efeitos danosos, a sociedade e as comunidades organizam-se em defesa do direito às políticas públicas.

Em 14 (quatorze) de outubro de 2020, foi votado o PL 529/2020 e transformado em norma sob a Lei estadual $n^{\circ}$ 17.293/2020. Com efeito, a Fundação ITESP foi vetada da lista de órgãos extintos, prevista no projeto de lei. Porém, não há segurança referente aos recursos que serão destinados à fundação ITESP principalmente para reconhecimento e titulação dos territórios quilombolas.

Até o momento, não se encontrou nenhum fato ou argumento que legitimasse o PL n 529/2020, em face à extinção da Fundação ITESP, já que o governo não realizou nenhum estudo ecomônico ou social para justificar a argumentação de "ajuste fiscal e equilíbrio nos gastos públicos", seja na perspectiva das comunidades tradicionais quanto aos demais beneficiários da política pública de ATER paulista.

\section{Referências}

ALMEIDA, M. G. Território quilombola, etnodesenvolvimento e turismo no nordeste de Goiás. Revista Ra'e Ga. UFPR: Curitiba, v.40, p. 130 -144. Ago/2017. Disponível em https://revistas.ufpr.br/raega/article/view/46121/32970. Acesso em: 21 out. 2020.

BRASIL. Decreto $n^{\circ} 4.887$, de 20 de novembro de 2003. Disponível em http://www.planalto.gov.br/ccivil_03/decreto/2003/d4887.htm. Acesso em:20 out. 2020.

BRASIL. PNATER - Política Nacional de Assistência Técnica e Extensão Rural. Versão final. Brasília: MDA, maio de 2004.

BRASIL. PRONATER. Programa Nacional de Assistência Técnica e Extensão Rural 2005. Disponível em www.faser.org.br/anexos/Pronater.doc. Acesso em: 25 out. 2020. 
BRASIL. Lei 10.207 de 8 de janeiro de 1999. Disponível em

<https://www.al.sp.gov.br/repositorio/legislacao/lei/1999/lei-10207-

08.01.1999.htm>Acesso em: 14 jan. 2021.

BRASIL. Lei 12.188 de 11 de janeiro de 2010. Disponível em http://www.planalto.gov.br/ccivil_03/_Ato2007-2010/2010/Lei/L12188.htm .

Acesso em: 26 out. 2020.

BRASIL Lei $n^{\circ} 12.293$ de 15 de outubro de 2020. Disponível em. https://www.al.sp.gov.br/repositorio/legislacao/lei/2020/lei-17293-

15.10.2020.html

Acesso em: 14 jan. 2021.

BRASIL Decreto no 9.064 de 31 de maio de 2017. Dispõe sobre a Unidade Familiar de Produção Agrária, institui o Cadastro Nacional da Agricultura Familiar. Disponível em https://www2.camara.leg.br/legin/fed/decret/2017/decreto-9064-31-maio2017-785001-publicacaooriginal-152929-pe.html. Acesso em: 03 nov. 2020.

CARRIL, L. F. B. Os desafios da educação quilombola no Brasil: o território como contexto e texto. Revista Brasileira de Educação. v. 22, n. 69, 2017. Disponível em https://www.scielo.br/pdf/rbedu/v22n69/1413-2478-rbedu-22-69-0539.pdf. Acesso em: 28 out. 2020.

CAPORAL, F.R.; COSTABEBER, J.A. Agroecologia e extensão rural: contribuições para a promoção do desenvolvimento rural sustentável. Brasília, MDA/SAF, 2004.

FUNDAÇÃO CULTURAL PALMARES. IBGE vai incluir informações quilombola no censo de 2020. Disponível em http://www.palmares.gov.br/?p=55555. Acesso em: 25 out. 2020.

GERHARDT, T.E.; SILVEIRA, D.T. Métodos de pesquisa. Porto Alegre: Editora da UFRGS, v. 2, 2009.

GIL, A. C. Métodos e técnicas de pesquisa social. 6 ed. São Paulo: Atlas, 2014.

MARCONI, M. A.; LAKATOS, E. M. Técnicas de pesquisa: planejamento e execução de pesquisas, amostragens e técnicas de pesquisa, elaboração, análise e interpretação de dados. 7 ed. São Paulo: Atlas, 2013.

MOURA, G. Proposta Pedagógica. In: Educação Quilombola. Disponível em http://www.portal.educacao.salvador.ba.gov.br/site/documentos/espacovirtual/es paco-diversidade/----ARTIGO/Educacao-quilombola.pdf. Acesso em: 12 out. 2020.

OLINGER, G. Aspectos Históricos da Extensão Rural no Brasil e em Santa Catarina. Florianópolis: Epagri, 2020.

PEREIRA, L. S.; MENDES, N. S. A Educação Quilombola para as Comunidades Remanescentes de Quilombo, uma Análise da Obra Educação Quilombola. Anais do IV CEPE. Congresso de Ensino, Pesquisa e Extensão da UEG 2017.

RUA, M. G. Análise de políticas públicas: conceitos básicos. In: RUA, M. G; CARVALHO, M. I. V. (org.). O estudo da política: tópicos selecionados. Brasília: Paralelo 15, 1998, p 231-261.

SÃO PAULO. Estado de São Paulo. ITESP. Comunidades remanescentes de quilombos. Sem data. Disponível em: http://201.55.33.20/?page_id=3483. Acesso em: 15 out. 2020.

SÃO PAULO. Estado de São Paulo. Projeto de Lei 529 de 13 de agosto de 2020. Disponível em: https://www.al.sp.gov.br/propositura/?id=1000332222. Acesso em:22 set. 2020.

SARAVIA, E. Introdução à Teoria da Política Pública. In: SARAVIA, Enrique; FERRAREZI, Elisabete (Org.) Políticas públicas: coletânea, v. 2. Brasília: ENAP, 2006.

SCHMITT, A.; TURATTI, M. C. M.; CARVALHO, M. C. P. A atualização do conceito de quilombos: identidade e território nas relações teóricas. Ambiente \& Sociedade Ano V - n. $10-1^{\circ}$ Semestre de 2002.

SOUZA, C. Políticas públicas: uma revisão da literatura. Sociologias, n. 16, p. 20-45, 2006. 


\section{revisto \\ Observatório}

e-ISSN n' 2447-4266

Palmas, v. 7, n. 1, p. 1-12, jan.-mar., 2021

http://dx.doi.org/10.20873/uft.2447-4266.2021v7n1a5pt

VIEIRA, S. C. O papel do extensionista no fluxo de informações entre pesquisadores do agronegócio e produtores rurais. Dissertação de mestrado. PGAD. UNESP - FCE. Tupã. 2016. Disponível em https://repositorio.unesp.br/bitstream/handle/11449/143426/vieira_sc_me_tupa.p df sequence=4\&isAllowed=y. Acesso em: 25 set. 2020.

VIEIRA, S. C.; BERNARDO, C. H.; LOURENZANI, A. E. B. S.; SATOLO, E. G.. La historia de la extensión agrícola en Brasil: de la reproducción a la reflexión. Historia Actual Online, v. 52, p. 45-56, 2020. Disponível em https://historiaactual.org/Publicaciones/index.php/hao/article/view/1868. Acesso em: 15 out. 2020.

\begin{abstract}
:
The remaining quilombo communities at the São Paulo State in Brazil are in serious risk of negative changes in the provision of official rural extension services with the advent of state Bill $n^{\circ} 529 / 2020$. The objective of this research is to evaluate how the traditional remaining quilombo communities located at São Paulo State can be directly affected nega-tively by the law proposal. For this, a scientific methodology was adopted, which is sum-marized in the review bibliographic and descriptive and exploratory documentary. As a result, no fact or argument has been found that legitimizes Bill $n^{\circ} 529$ of 2020 from the perspective of traditional communities and other beneficiaries of the São Paulo ATER public policy.
\end{abstract}

KEYWORDS: Quilombos from São Paulo; Rural extension; Traditional communities.

\begin{abstract}
RESUMEN:
Las comunidades de quilombos restantes en el estado de São Paulo corren un grave riesgo de cambios negativos en la prestación de servicios oficiales de extensión rural con la lle-gada del proyecto de ley 529/2020. El objetivo de esta investigación es buscar cómo las comunidades tradicionales de quilombo restantes ubicadas en el estado de São Paulo pueden ser perjudicadas directamente con la PL 529 de 2020. Para ello, se adoptó una metodología científica, que resume la revisión bibliográfica y documental. Carácter des-criptivo y exploratorio. A consecuencia, no se ha encontrado ningún hecho o argumento que legitime el Proyecto de Ley $n^{\circ} 529$ de 2020 desde la perspectiva de las comunidades tradicionales y otros beneficiarios de la política pública ATER de São Paulo.
\end{abstract}

PALABRAS-CLAVES:

Comunidades tradicionales; Extensión rural; Quilombos de São Paulo. 